\title{
Search Frictions, Efficiency Wages and Equilibrium Unemployment
}

\author{
CHRIS MARTIN \\ University of Bath
}

BINGSONG WANG

University of Warwick

\begin{abstract}
This paper explores the decomposition of equilibrium unemployment into involuntary and frictional components using a model that combines efficiency wages with search and matching frictions in the labour market. In deriving our results we generalise the celebrated Solow Condition, expressing the wage as the sum of a pure efficiency wage component and a component that reflects search frictions. Using standard values of calibrated parameters, we find that the bulk of unemployment is involuntary.
\end{abstract}

Keywords: efficiency wages, search frictions, equilibrium unemployment

JEL Classifications: E23, E32, J23, J30, J64

\section{Introduction}

Economists distinguish two main types of unemployment. The first is frictional unemployment, reflecting search and matching frictions in the labour market (e.g. Pissarides, 2000). The second is involuntary unemployment, typically explained by invoking either efficiency wage effects or union-firm bargaining. These have different causes: frictional unemployment is rooted in the imperfect matching between unemployed workers and available vacancies that is characteristic of large, dispersed economies, whereas involuntary unemployment is centered around wage determination and associated issues of bargaining power and worker motivation. They also imply different policy responses: frictional unemployment can be addressed by improving information about available opportunities and by re-training workers to make them better suited for available vacancies, while involuntary unemployment can be addressed by reforming wage determination and the unemployment compensation system. Although frictional and involuntary unemployment have both been analysed extensively, the issue of their relative importance in explaining observed unemployment has not been explored in as much depth. This is an im-

*Corresponding author: c.i.martin@bath.ac.uk

(c) 2018 Chris Martin, Bingsong Wang. Licenced under the Creative Commons AttributionNoncommercial 3.0 Licence (http://creativecommons.org/licenses/by-nc/3.0/). Available at http://rofea.org. 
portant issue for economists and policymakers: if frictional unemployment is a more important determinant of the unemployment rate, then economists can focus more on understanding the forces that give rise to it and policymakers can place more emphasis on mitigating its effects.

In this paper, we analyse the relative size of frictional and involuntary unemployment in steady-state. In order to analyse involuntary unemployment, we need an explicit model of wage determination. We do this by incorporating a generic representation of efficiency wage effects due to Solow (1979) into a simple DSGE model with labour market search frictions. Using this model, we decompose steady-state unemployment into two components, the first due to involuntary unemployment and the other reflecting frictional unemployment. Calibrating our model using parameter values popular in the literature, we find that the majority of state-state unemployment can be classified as being involuntary. This benchmark value suggests that a policy focus on the root causes of involuntary unemployment might be a priority.

Our analysis is grounded in the search frictions models developed by Diamond (1982), Mortensen and Pissarides (1994) and Pissarides (2000) (see Ljungqvist and Sargent, 2017, for a more recent contribution), extended to include DSGE features by, for example, Krause and Lubik (2007) and Blanchard and Gali (2010). Michaillat (2012) analyses a model in which frictional and involuntary unemployment co-exist; he uses a pure search frictions model based on a bargaining approach to wage determination with real wage rigidity, rather than an efficiency wage model, to construct time series for frictional and involuntary unemployment. Malcomson and Mavroeidis (2007) analyse the relative sizes of frictional and involuntary unemployment using a different type of efficiency wage effect, the shirking model developed by Shapiro and Stiglitz (1984) but do not quantify the relative size of the two types.

The paper is structured as follows. We outline our model in section 2) and characterise optimal wage-setting by the firm. The wage is the sum of two components; the first due to efficiency wage effects and the second reflecting labour market frictions. Labour market frictions increase the wage. Intuitively, this is because output depends on effective labour input, the product of employment and effort per worker. An increase in hiring costs induces firms to adjust the composition of effective labour, increasing effort relative to employment. This is achieved through an increase in the wage. We analyse the aggregate steady-state unemployment rate in section 3) and show how it can be decomposed into involuntary and frictional components. Section 4) presents a calibration of our model. Using standard values from the search-and-matching and efficiency wage literatures to calibrate our structural parameters, we show that the large majority of steady-state unemployment in our model is involuntary. Section 5) summarises and concludes.

\section{The Model}

In this section, we analyse wage and employment determination, drawing on a DSGE model with search frictions in the labour market. For brevity and clarity, we do not outline all as- 
MARTIN, WANG Search Frictions, Efficiency Wages and Equilibrium Unemployment

pects of the model. Our analysis is based on a discrete time model of undirected search with identical workers and firms. Following the literature on search frictions, as summarised in Pissarides (2000), we assume that a worker inelastically supplies labour and is either employed or unemployed. If employed, they receive the wage; if unemployed, they receive unemployment benefits. We depart from the standard search frictions literature in two respects. We assume that the wage is posted by the firm rather than determined through wage bargaining. We also assume that output depends on the amount of effort expended by the worker. The worker chooses effort to balance, at the margin, two offsetting effects: a dislike of exerting effort and a reciprocity effect through which the worker derives utility from responding to a generous wage offer from the firm by increasing effort, or from "punishing" a low wage offer from the firm by reducing effort; evidence for the reciprocity effect includes Kahneman et al (1986), Bewley (1999) and Fehr et al (2009).

To formalise effort determination, we assume the worker has a disutility of exerting effort given by $c\left(e_{t}\right)$, where $e$ is effort, and follow Rabin (1993) and Danthine and Kurmann (2007) by assuming that the utility from reciprocity is given by $R\left(e_{t}, W_{t}, \bar{W}_{t}\right)=g\left(W_{t}, \bar{W}_{t}\right) d\left(e_{t}\right)$ where $W$ is the wage and $\bar{W}_{t}$ is a reference wage. The worker chooses effort to minimise $c\left(e_{t}\right)$ $R\left(e_{t}, W_{t}, \bar{W}_{t}\right)$. The optimal level of effort is therefore characterised by $c_{e}\left(e_{t}\right)=d_{e}\left(e_{t}\right) g\left(W_{t}, \bar{W}_{t}\right)$. Solving this for effort, we obtain the optimal supply of effort function as

$$
e_{i t}=e\left(W_{i t}, \bar{W}_{t}\right)
$$

We assume that output at representative firm $i$ at time $t$ depends on employment and effort expended by workers

$$
Y_{i t}=A_{t} F\left(e_{i t} N_{i t}\right)
$$

where $N$ is employment, $A_{t}$ is technology, given by $A_{t}=A e^{z_{t}}$, where $z_{t}$ is a productivity shock and we assume $F^{\prime}\left(\right.$.) $>0$ and $F^{\prime \prime}() \leq$.0 . Employment evolves according to

$$
N_{i t}=(1-\tau) N_{i t-1}+h_{i t}
$$

where $h$ is the number of workers hired and $\tau$ is the exogenous job separation rate. The labour market is characterised by search frictions and so firms must post vacancies in order to hire workers. We assume the aggregate matching function is $h_{t}=M\left(U_{t}, V_{t}\right)$ where $h$ are aggregate hires, $U$ is the number of job seekers and $V$ are aggregate vacancies; we assume $M_{U}()>$.0 , $M_{V}()>0,. M_{U U}() \leq$.0 and $M_{V V}() \leq$.0 . We also assume the matching function has constant returns to scale, so $h_{t}=V_{t} M\left(\frac{U_{t}}{V_{t}}, 1\right)$, hence the vacancy filling rate $q_{t}$ is given by $q_{t}=\frac{h_{t}}{V_{t}}=$ $\bar{M}\left(\frac{U_{t}}{V_{t}}\right)$, where $\bar{M}\left(\frac{U}{V}\right)=M\left(\frac{U}{V}, 1\right)^{1}$. We further assume that the number of workers hired by firm

\footnotetext{
${ }^{1}$ These assumptions are satisfied by the widely using matching function $h_{t}=m U_{t}^{\alpha} U_{t}^{1-\alpha}$
} 
$i$ is proportional to the relative number of vacancies it posts, so $h_{i t}=\frac{V_{i t}}{V_{t}} h_{t}$, where $V_{i t}$ is the number of vacancies posted by the firm. As a result, $q_{i t}=\frac{h_{i t}}{V_{i t}}=q_{t}$ and so the vacancy filling rate is exogenous at the level of firm. Firms are monopolistic competitors with demand function

$$
\frac{Y_{i t}}{Y_{t}}=\left(\frac{P_{i t}}{P_{t}}\right)^{-\epsilon}
$$

where $P_{i t}$ is the price set by firm, $Y_{t}$ is aggregate output and $P_{t}$ is the aggregate price ${ }^{2}$. We follow the literature on search frictions in assuming the unit cost of a vacancy is $\gamma_{t}=\bar{\gamma} A_{t}$. Per-period profit for firm $i$ is

$$
\pi_{i t}=P_{i t} Y_{i t}-W_{i t} N_{i t}-\gamma_{t} V_{i t}
$$

In an efficiency wage context, the firm chooses employment and the wage. The value function for the firm is then

$$
V\left(N_{i t-1}\right)=\max _{\left\{W_{i t}, N_{i t}\right\}}\left\{\pi_{i t}+\beta_{t} E_{t} V\left(N_{i t}\right)\right\}
$$

where $\beta_{t}$ is the stochastic discount factor, since $N_{i t-1}$ is a state variable in period $t$. Effort is not observed by the firm, but the firm knows the effort function in (1). Using (1)-(4) the first-order condition for the wage is

$$
\frac{P_{i t}}{\mu} A_{t} F^{\prime}(.) e^{\prime}\left(W_{i t}\right)=1
$$

where $\mu=\frac{\epsilon}{\epsilon-1}$ is the mark-up of price over marginal cost. The first-order condition for employment is

$$
\frac{P_{i t}}{\mu} A_{t} F^{\prime}(.) e_{i t}=W_{i t}+\bar{\gamma} \frac{A_{t}}{q_{i t}}-\beta_{t} \bar{\gamma}(1-\tau) E_{t} \frac{A_{t+1}}{q_{i t+1}}
$$

where the RHS of (8) is the present value of the marginal cost of a new hire, composed of the wage plus the present value of hiring costs, the cost of hiring an additional worker in the current period less the expected present value of the reduction in future hiring costs implied by this hire ${ }^{3}$.

These imply an extension to the Solow Condition, given by

$$
\frac{W_{i t} e^{\prime}\left(W_{i t}\right)}{e_{i t}}=\frac{1}{1+\frac{\bar{\gamma}}{W_{i t}}\left(\frac{A_{t}}{q_{i t}}-\beta_{t}(1-\tau) E_{t} \frac{A_{t+1}}{q_{i t+1}}\right)}
$$

\footnotetext{
${ }^{2}$ This is a standard relationship in DSGE models, where $Y_{t}=\left\{\int_{0}^{1} Y_{j t}^{\frac{\varepsilon-1}{\epsilon}} d\right\}^{\frac{\varepsilon}{\epsilon-1}}$ and $P_{t}=\left\{\int_{0}^{1} P_{j t}^{1-\varepsilon} d\right\}^{\frac{1}{1-\varepsilon}}$, where is the elasticuty of substitution between different goods in consumption; see, eg Miao ( 2014)

${ }^{3}$ This is the standard optimality condition for firms in this type of model (eg Miao, 2014, chapter 18), extended to allow for effort effects.
} 
At the optimum, the elasticity of effort w.r.t the wage equals the ratio of the wage to the present value of the cost of a new hire. In the absence of labour market frictions, this simplifies to the original Solow condition.

To proceed, we assume that $c\left(e_{t}\right)=\frac{\omega e_{t}^{1+\varphi}}{1+\varphi}, d\left(e_{t}\right)=\frac{\kappa e_{t}^{1+\chi}}{1+\chi}$ and $g\left(w_{t}\right)=\left(\frac{W_{i t}-\bar{W}_{t}}{\bar{W}_{t}}\right)$. The optimal supply of effort is then

$$
e\left(W_{i t}, \bar{W}_{t}\right)=\bar{e}\left(\frac{W_{i t}-\bar{W}_{t}}{\bar{W}_{t}}\right)^{\sigma}
$$

where $\sigma=\frac{1}{\varphi-\chi}$. This corresponds to the effort function assumed by Summers (1988). Combining this with (7) and (8), the optimal wage is obtained as

$$
W_{i t}=\frac{1}{1-\sigma} \bar{W}_{t}+\frac{\sigma}{1-\sigma} \bar{\gamma}\left(\frac{A_{t}}{q_{i t}}-\beta_{t}(1-\tau) E_{t} \frac{A_{t+1}}{q_{i t+1}}\right)
$$

The wage has two distinct components. The first is a pure efficiency wage effect in which the wage is a mark-up over the reference wage, where the mark-up reflects the strength of efficiency wages. The second reflects labour market frictions as the worker receives a proportion of the present value of hiring costs, where this proportion also reflects the strength of efficiency wage effects. The impact of hiring costs on wages arises from the fact that firms determine both the size and the composition of effective labour input $\left(e_{i t} N_{i t}\right)$. In response to an increase in hiring costs, firms increase effort relative to employment, achieving this through an increase in the wage.

\section{Equilibrium Unemployment}

To analyse unemployment we aggregate the firm-level relationships derived above and consider steady-state outcomes. In order to obtain an explicit solution, we assume that the matching function is $M\left(U_{t}, V_{t}\right)=m U_{t}^{\alpha} V_{t}^{1-\alpha}$. Using $h=\tau N$, the vacancy filling rate is a function of unemployment: $q(U)=m\left(\frac{m U}{\tau(1-U)}\right)^{\frac{\alpha}{1-\alpha}}$. We also assume $F\left(e_{i t} N_{i t}\right)=e_{i t} N_{i t}$ and that the reference wage is (e.g. Summers, 1988)

$$
\bar{W}_{t}=\left(1-\phi U_{t}\right) W_{t}^{a}
$$

where $W_{t}^{a}$ is the wage offered by other firms and $\phi$ measures the importance of unemployment in determining a worker's outside opportunity $(\phi>0)$. At the aggregate level, effort is also a function of unemployment: $e(U)=\bar{e}\left(\frac{\phi U}{1-\phi U}\right)^{\sigma}$. Imposing the equilibrium conditions $W_{i t}=W_{t}^{a}=$ $W_{t}$ and $P_{i t}=P_{t}$, the first-order conditions for the wage and employment become

$$
\frac{\sigma}{\mu} \frac{P A e(U)}{\phi U}=W
$$

and 


$$
\frac{1}{\mu} P A e(U)=W+\bar{\gamma} \frac{A(1-\beta(1-\tau))}{q(U)}
$$

Solving, we obtain

$$
e(U) q(U)\left(1-\frac{\sigma}{\phi U}\right)=\mu \hat{\gamma}
$$

where $\hat{\gamma}=(1-\beta(1-\tau)) \frac{\gamma}{P}$ is the present value of marginal hiring costs. Defining $U^{e w}=\frac{\sigma}{\phi}$, the steady-state unemployment rate is given by

$$
e(U) q(U)\left(1-\frac{U^{e w}}{U}\right)=\mu \hat{\gamma}
$$

In the absence of labour market frictions $(\hat{\gamma}=0)$, this simplifies to $U=U^{e w}$, the unemployment rate implied by a pure efficiency wage model. If there are labour market frictions, $U>U^{e w}$, giving an additional component to unemployment. Since $e(U)$ and $q(U)$ are increasing functions, the unemployment rate is an increasing function of the mark-up $(\mu)$, the responsiveness of effort to the wage $(\sigma)$, the separation rate $(\tau)$, vacancy costs $(\gamma)$; and a decreasing function of the efficiency of job matching $(m)$ and the weight on unemployment in the reference wage $(\phi)$.

Decomposing unemployment as

$$
U=U^{e w}+U^{f r}
$$

where $U^{f r}$ is the frictional component, (16) implies that

$$
U^{f r}=\lambda(U) U
$$

where $\lambda(U)=\frac{\mu \hat{\gamma}}{e(U) q(U)}$ and

$$
U^{e w}=(1-\lambda(U)) U
$$

\section{Calibration}

In this section, we investigate the relative sizes of the components of equilibrium unemployment using a calibration of the model. We calibrate the structural parameters of our model using widely used values in the existing literature and consider a quarterly frequency. We follow Shimer (2005) in setting the discount factor at $\beta=0.988$, the elasticity of hires with respect to unemployment at $\alpha=0.72$ and the efficiency of the matching function as $m=1.355$. We also follow Shimer in setting the cost of posting a vacancy as $\gamma=0.213$; this value lies in the range of calibrated values of $\gamma$ in the literature ${ }^{4}$. In the literature, monthly values of the separation

${ }^{4}$ The value of $\gamma$ is contentious. Shimer (2005) uses a quarterly vacancy cost of 0.213 . Hagedorn and Manovskii (2008) use a weekly vacancy cost of 0.584. Hall (2005) assumes a monthly cost of 0.986 while Pissarides (2009) assumes 0.356. 


\section{MARTIN, WANG Search Frictions, Efficiency Wages and Equilibrium Unemployment}

rate vary between 0.03 (Hall and Milgrom, 2008) and 0.036 (Pissarides, 2009); our choice of $\tau=0.12$ lies within this range and is also used by Gali $(2011)^{5}$. We use a price mark-up of $\mu=1.2$; this is a standard value in the New Keynesian literature. In calibrating the effects of endogenous effort, we draw on the estimates of an effort function analogous to (10) in Della Vigna and Pope (2016); we calibrate $\sigma=0.025$, which is towards the lower end of the estimates in that paper. We use $\phi=0.53$; this implies that unemployment compensation is $54 \%$ of wage income. This is between the values of 0.4 assumed by Shimer (2005) and 0.71 assumed by Hall and Milgrom (2008) and is within the range of $0.47-0.96$ estimated by Chodorow-Reich and Karabarounis (2016) based on alternative specifications of the flow value of non-work. Table 1) summarises our calibrated values.

Table 1. Calibration Parameters

\begin{tabular}{|c|c|c|c|c|c|c|c|c|}
\hline$\beta$ & $\alpha$ & $m$ & $\bar{\gamma}$ & $\tau$ & $\mu$ & $\sigma$ & $\phi$ & $\bar{e}$ \\
\hline 0.988 & 0.720 & 1.355 & 0.213 & 0.120 & 1.200 & 0.025 & 0.530 & 0.700 \\
\hline
\end{tabular}

These values impy a steady-state unemployment rate of $5.37 \%$; this is close to the postwar average US unemployment rate. They also imply an equilibrium job finding rate of $68 \%$, which is also close to the observed value in the US. The implied values of unemployment using the parameter values in Table 1) are presented in the first row of Table 2). The involuntary component of steady-state unemployment is $U^{e w}=4.72 \%$ and the frictional component is $U^{f r}=0.65 \%$. Thus $\lambda=0.122$, implying that roughly $12 \%$ of total unemployment in steadystate is frictional. This suggests that most unemployment in steady-state is due to the factors that drive involuntary unemployment, wage determination and the unemployment compensation system.

Although there are no comparator studies that also address this issue using a model with search frictions, our finding that steady-state unemployment is mainly driven by wage determination and unemployment compensation is consistent with the emphasis on these factors in the literature on the unemployment volatility puzzle. This literature has arisen following the demonstration by Shimer (2005) that simulations of the standard search frictions model, without effort effects, is unable to generate sufficient volatility of unemployment, vacancies and labour market tightness to match the large values observed in the data. Proposed "solutions" to this challenge have used a variety of alternative formalisations of wage bargaining (eg Hall and Milgrom, 2008) or alternative parameterisations (eg Hagedorn and Manovskii, 2008) but have not focussed on the matching function that generates labour market frictions.

We next consider a variety of changes to our parameterisation, to explore the robustness of this conclusion. Rows 2) and 3) of Table 2) use $\sigma=0.03$ and $\sigma=0.02$; although these

\footnotetext{
${ }^{5}$ Shimer (2005) uses the slighly lower value of $\tau=0.1$
} 
ange the steady-state rate of unemployment, they do not change the dominance of involuntary unemployment. Rows 4) and 5) use $\phi=0.63$ and $\phi=0.43$; here again there is no significant change in the relative importance of involuntary unemployment. We next vary the mark-up, considering $\mu=1$ and $\mu=1.4$; as rows 6) and 7) show, these changes affect the steady-state rate of unemployment but not the rate of involuntary unemployment. There is no marked change in the dominance of involuntary unemployment. Finally, rows 8) and 9) report results when $\gamma=0.11$ and $\gamma=0.35$; here again there is no change in the rate of involuntary unemployment and no change in the dominance of involuntary unemployment. These experiments suggest that the result that most unemployment in steady-state is due to involuntary unemployment is quite robust.

Table 2. Equilibrium Unemployment

\begin{tabular}{|c|c|c|c|c|}
\hline change from Table 1) & $U$ & $U^{e w}$ & $U^{\text {fr }}$ & $\lambda$ \\
\hline & $5.37 \%$ & $4.72 \%$ & $0.65 \%$ & 0.121 \\
\hline$\sigma=0.03$ & $6.18 \%$ & $5.66 \%$ & $0.52 \%$ & 0.083 \\
\hline$\sigma=0.02$ & $4.60 \%$ & $3.77 \%$ & $0.83 \%$ & 0.180 \\
\hline$\phi=0.63$ & $4.76 \%$ & $3.97 \%$ & $0.79 \%$ & 0.167 \\
\hline$\phi=0.43$ & $6.31 \%$ & $5.81 \%$ & $0.49 \%$ & 0.078 \\
\hline$\mu=1$ & $5.27 \%$ & $4.72 \%$ & $0.56 \%$ & 0.106 \\
\hline$\mu=1.4$ & $5.54 \%$ & $4.72 \%$ & $0.82 \%$ & 0.148 \\
\hline$\gamma=0.11$ & $5.15 \%$ & $4.72 \%$ & $0.44 \%$ & 0.085 \\
\hline$\gamma=0.35$ & $5.92 \%$ & $4.72 \%$ & $1.20 \%$ & 0.203 \\
\hline
\end{tabular}

\section{Conclusions}

In this paper we have combined a generic representation of efficiency wage effects with a search and matching model in order to decompose steady-state unemployment into a component due to involuntary unemployment and a component reflecting frictional unemployment. We have also derived a simple generalisation of the Solow Condition, from which we used to express the wage as the sum of efficiency wage and search-and-matching components. Calibrations of our model suggest that over $85 \%$ of steady-state unemployment is involuntary.

We would argue that our results are interesting but not definitive. We would wish to develop our work, in three main directions. First, more work is needed to establish the generality of our findings. Second, we should investigate why the contribution of frictional unemployment is so small. We suspect that this in part reflects the specific form for the effort function used in this paper. Thirdly, our decomposition is only for the equilibrium rate of unemployment. A natural extension of our work would analyse the decomposition of unemployment away from steady-state. We hope to address these issues in further work. 
MARTIN, WANG Search Frictions, Efficiency Wages and Equilibrium Unemployment

\section{References}

Bewley, T. F., (1999), ’Why Wages Don’t Fall During a Recession”, Harvard University Press, London.

Blanchard, O and J Gali, (2010), "Labor Markets and Monetary Policy: A New Keynesian Model with Unemployment", American Economic Journal: Macroeconomics, 2(2): 1-30.

Chodorow-Reich, G. and L. Karabarbounis, (2016), "The Cyclicality of the Opportunity Cost of Employment", Journal of Political Economy, vol. 124(6), 1563-1618.

Danthine, J.-P. and Kurmann, A., (2007), 'The Macroeconomic Consequences of Reciprocity in Labor Relations", Scandinavian Journal of Economics, 109(4), 857-881

Della Vigna, S. and D. Pope, (2016), "What Motivates Effort? Evidence and Expert Forecasts", Review of Economics Studies, forthcoming.

Diamond, P. (1982): "Aggregate Demand Management in Search Equilibrium", Journal of Political Economy, Vol. 90(5), 881-94.

Fehr, E., Goette, L., and Zehnder, C., (2009), "A Behavioral Account of the Labor Market: The Role of Fairness Concerns. Annual Review of Economics, 1(1):355-384.

Gali, J. (2011): "Monetary Policy and Unemployment", Handbook of Monetary Economics, Volume 3A.

Hagedorn, M. and Y. Manovskii (2008): "The Cyclical Behavior of Unemployment and Vacancies Revisited". American Economic Review, 98(4),1692-1706.

Hall, R., and Milgrom, P. (2008), "The Limited Influence of Unemployment on the Wage Bargain", American Economic Review, Vol.95, No.1.

Kahneman, D., Knetsch, J. L., and R.H. Thaler, (1986), "Fairness as a Constraint on Profit Seeking : Entitlements in the Market. American Economic Review, 76(4):728-741

Krause, M. U. and T. A. Lubik (2007), "The (Ir)relevance of Real Wage Rigidity in the New Keynesian Model with Search Frictions", Journal of Monetary Economics, 54, 706-727.

Ljungqvist, L., and Sargent, T., (2017), "The Fundamental Surplus", American Economic Review, 9, 2630-65

Malcomson J.M. and S Mavroeidis, (2007): " Matching frictions, efficiency wages, and unemployment in the USA and the UK", Brown University Working Paper, 2007-02.

Miao, J, (2014), "Economic Dynamics in Discrete Time", MIT Press, Cambridge Ma.

Michaillat, P. (2012): "Do Matching Frictions Explain Unemployment? Not in Bad Times", American Economic Review, Vol. 102(4), 1721-50.

Mortensen, D. and Pissarides, C. (1994): "Job Creation and Job Destruction in the Theory of Unemployment", The Review of Economic Studies, Vol. 61

Pissarides, C. (2000): "Equilibrium Unemployment Theory (2nd edition)", MIT Press

Pissarides, C. (2009): "The Unemployment Volatility Puzzle: is Wage Stickiness the Answer?" Econometrica, 77(5),1339-1369. 
Rabin, M., (1993), "Incorporating Fairness into Game Theory and Economics", American Economic Review, 83(5), 1281-1301.

Shapiro, C and J Stiglitz, (1984): "Equilibrium Unemployment as a Worker Discipline Device", American Economic Review, Vol. 74(3), 433-444.

Shimer, R, (2005): "The Cyclical Behavior of Equilibrium Unemployment and Vacancies", American Economic Review, Vol. 95(1), 25-49.

Solow, R. (1979): "Another possible source of wage stickiness", Journal of Macroeconomics 1, 79-82.

Summers, L.H. (1988): "Relative wages, efficiency wages and Keynesian unemployment", American Economic Review 78, 383-388 